\title{
Incentives for non-participation: absence in the United Kingdom House of Commons, 1997-2015
}

\author{
Zoltán Fazekas \\ Copenhagen Business School \\ $z f . e g b @ c b s . d k$
}

\author{
Martin Ejnar Hansen \\ Brunel University London \\ martin.hansen@brunel .ac.uk
}

\section{Preprint: Paper accepted in Public Choice. For final version and citation, please refer to the journal article.}

\begin{abstract}
The ability to hold MPs accountable for their actions is one of the cornerstones of modern representative democracy. While it is important for MPs to send signals to both their constituents and to their party, a large number of MPs remain absent from votes. Those absences are an important part of the MP's toolbox, but absences carry limitations, rooted in electoral and political constraints. We investigate how-conditional on the electoral cyclesome well-established political constraints along the government and opposition lines vary in strength. We examine the absence probabilities of MPs in the United Kingdom from 1997 to 2015, and find that as the next elections are approaching, political constraints somewhat weaken and electoral ones take over, but marked differences emerge between parliamentary sessions.
\end{abstract}




\section{INTRODUCTION}

Many bills are passed with large proportions of legislators absent, which can limit constituents' ability to make informed accountability judgments (Arnold 1992). While public service motivations of legislative activity suggest that representatives should mostly be present (Staats 1988), absence becomes a tool for prioritizing tasks and managing workloads (Cain, Ferejohn, and Fiorina 1979; Fenno 1977). However, decisions to be absent can be costly. The interest in legislator activity is well-documented in the public choice literature with Anthony Downs' seminal work (Downs 1957) and later Riker and Ordeshook (1968) setting the baseline for a considerable literature studying, for instance, the choice of voting or not voting for legislators (for example Amacher and Boyes 1978; Dougan and Munger 1989; Barro 1973; Lott 1987). How legislators act collectively is also understood from the perspectives of Buchanan and Tullock (1965) or Olson (1965). In many ways, those perspectives remain part of the foundation on which studies of legislative decision-making implicitly build; the present article is no different.

Legislators need to ensure that they do enough for their party to get re-selected as candidates (in terms of supporting legislation), but not so much that it might interfere with services to their constituents, which drive reelection hopes. Constituency work often means obligations outside of parliament (Cain, Ferejohn, and Fiorina 1984) and such work might contribute to voters' favorable evaluations (Vivyan and Wagner 2016). At the same time, MPs in parliamentary systems are governed by strong parties: the most important goal for the governing party is to pass its policies (Johnston et al. 2002). Party discipline is especially salient in the Westminster system, wherein the divide between the government and opposition influences voting behavior and, moreover, the government has very strong legislative agenda setting power (Hix and Noury 2016; Döring 1995). Overall, such a two-principal (constitutents and parties) setup imposes political and electoral constraints (Carey 2007).

We ask in this paper how political and electoral constraints affect MPs' decisions to be absent and how might MPs resolve the tension between the constraints. We rely on voting data from four parliaments (1997 to 2015) in the UK's House of Commons (HoC), which allow us to examine the topic over a longer time horizon in a non-US setting with strong parties and a powerful individualized electoral system, along with with a changing government-opposition constellation. Thus, we also extend the discussion on how institutionally dependent our general absence conceptualization is.

We show that government MPs face stronger political constraints than do opposition MPs, which manifests itself in the former's lower absence rates. Furthermore, electoral constraints play an important role as well: MPs' absences increase as the next elections are approaching. However, less is known about how the two constraints interact. In that regard, we present evidence that the absence difference between government and opposition MPs declines throughout the legislative period, indicating that electoral constraints are strong enough to override the political constraints, freeing up government MPs' time for constituent service. However, we also find substantial heterogeneity between legislatures, further highlighting the role of political context and parliamentary reality. Our insights also contribute to better understanding governmental agenda control in the House of Commons, especially how government MPs can be freed up, when needed, towards the end of the legislative term.

Overall, the contribution of the article is three-fold. First, by examining voting data from four parliaments we explore whether MPs act strategically in terms of their decisions to be absent from votes while controlling for the presence of political and electoral constraints. Second, by focusing 
on both political and electoral constraints and, in particular, their interactions, we advance the theoretical perspective on the study of absence, while also contributing empirically to the body of knowledge on the UK's Parliament, for which the lack of interest in MP absence remains remarkable. Thirdly, our study offers an additional perspective on the importance of government agenda-control for MP decision-making, both extending and adding insights regarding the government's potential power.

\section{Political and Electoral constraints of ABSEnce}

Absence refers to the situation when an MP or representative is not present for a vote in the legislative body. Kam (2009) distinguishes between 'simple' and 'deliberate' absence, where the latter is similar to position avoidance. In such cases absence is non-random and non-ignorable for roll call analysis (Rosas, Shomer, and Haptonstahl 2015; Rosas and Shomer 2008) and can be a lower cost alternative to dissent, if MPs want to avoid position taking. ${ }^{1}$

Analogous to questions of party unity (Carey 2007), the decision to be absent is framed as a 'competing principals' question. This framework can be extended even for cases where absence is not used for avoiding unattractive positions on a bill, by regarding principals more generally. This is especially important, because only few parliaments allow researchers to outright distinguish between absence and abstention (see for example the Swedish Riksdag in Willumsen and Öhberg 2017). Indeed, there is no way to officially record an abstention in the HoC, thus abstention becomes an available option for British MPs in the form of absence. ${ }^{2}$

Most previous research focuses on electoral and political constraints ${ }^{3}$, since these map well to the idea of constituents and political parties (or legislative party groups) as principals, although sometimes both principals affect electoral or political constraints. When studying different constraints or principals, we need to highlight context specific characteristics. Given the strength of political parties in the United Kingdom, an MP cannot necessarily choose her position on bills and votes independently of the party. This has two implications.

First, the parties use party whips to control the voting, specifically the pairing tool for absences. Pairing is an informal tool which in effect allows a member from the government and one from the opposition to be absent simultaneously, i.e. not changing the power balance between government and opposition (see Crewe 2015, pp. 69-72). Given the informal nature of pairing there is no way of a priori knowing which absent members are paired to be absent and who are not (Crewe 2015). Second, it is also challenging to establish ideal positions of individual MPs, whether from candidate studies with weak response rates (Benedetto and Hix 2007) or from actual parliament votes (Spirling and McLean 2007; Spirling and Quinn 2010). These features point to the presence of political constraints associated with the party as principal, however these might vary in strength. In essence, political constraints are potential restrictions to what MPs can do (formal and informal) due to their role in any parliamentary activities, where the main principals limiting or enabling the MPs are the parties, with the potential to punish or reward them.

\footnotetext{
${ }^{1}$ Despite the rare-event nature of rebellions, much more attention has been given to those situations where MPs vote against their party (Cowley 2002; Benedetto and Hix 2007; Slapin et al. 2018). While evidence from the US suggests that there is little effect of rebelling (Donnelly 2019), survey evidence from the United Kingdom suggests some electoral benefits to be gained by rebelling (Campbell et al. 2019).

${ }^{2} \mathrm{~A}$ possibility is to vote in both the Aye and No lobbies, although this is extremely infrequent in use, and also used if a member has voted in the wrong lobby to nullify their original vote (Divisions in the House of Commons: House of Commons Background Paper, Standard Note: SN/PC/06401, Last updated: 2 August 2013).

${ }^{3}$ For the potential role of institutional constraints see Fortunato and Provins (2017).
} 
On the one hand, political constraints are weaker for more senior MPs who tend to be absent more frequently (Longley 2003), potentially because they are more familiar with formal and informal rules that govern parliamentary behavior or their personal status. On the other hand, from the literature on dissent we know that political constraints are stronger if one's own party or committee proposed the bill (Willumsen and Goetz 2017). From studies of absence we do know that the political constraints are stronger when a vote is more salient for the party (Forgette and Sala 1999). Furthermore, according to Cohen and Noll (1991), those few who decide not to turn out for such salient votes use their absences purposely in order to enhance influence and payoff, especially when they perceive the result to be very close. However, the generalization of the findings by Cohen and Noll are critiqued by Rothenberg and Sanders (1999, p. 314) who argue that since Cohen and Noll (1991) only look at one issue and one point in time they are excluding the possibility of variation across the election cycle, the findings must be treated with caution.

Members of the UK HoC are elected in single-member districts with the candidate achieving the most votes winning. This generates a strong link between representatives and the electorate who can reward or punish their representative more directly. This feature gives rise to a set of electoral constraints associated with the constituent(s) as principal. Electoral constraints are potential restrictions to what MPs can do (formal and informal) due to their goal of being viewed favorably among the electorate and potentially get re-elected, where the main principals limiting or enabling the MPs are the constituents, with the potential to punish or reward them at the time of elections. Research from the British context has shown that targeting in constituencies and general activism is important for the overall results (Fisher et al. 2014; Fisher et al. 2016), therefore making constituency activity by the MP important for reelection chances (Whiteley and Seyd 1994; Whiteley and Seyd 2003). Ultimately, in terms of voter preferences in Britain, a moderate balance of legislative and constituency work is preferred (Vivyan and Wagner 2016). Prior research documents a consistent "last-term effect" across different systems as retiring MPs decrease their presence in the legislature (Bailer and Ohmura 2018; Jones 2003; Lott 1987; Lott 1990; Willumsen and Goetz 2017; Geys and Mause 2016).

Furthermore, absence is influenced by other constituency features, such as transactional costs. In the US setting, one such transactional cost is related to geographical distance to the capitol (Hart and Munger 1989; Rothenberg and Sanders 1999), which is positively associated with absence rates. While earlier studies of $\mathrm{HoC}$ found no relationship between distance and absence (only expenses and costs) (Besley and Larcinese 2011), a recent study indicated very similar effects of distance to those found in the United States in the United Kingdom as well (Willumsen 2019). Overall, less is known about how MPs use absence as a tool in Westminster systems. We have seen that considerations from dissent might be useful as a broader framework, but institutional specificity stemming from the role of parties and the electoral system requires more detailed theoretical and empirical research.

\section{BALANCING CONSTRAINTS}

Strong political constraints would indicate more time spent in the parliament, whereas electoral or constituency focus would result in more time away from the parliament, in relative terms. For example, Zupan (1991) found that Democrats turned out less for votes than Republicans due to a greater focus by Democrats on constituency services. This then creates some tension (Norris 1997), where the role or strength of these constraints might be changing. We develop this juxtaposition and focus here on government $v s$ opposition related political constraints on the one hand, and changing electoral constraints depending on the electoral cycle on the other hand. 
First, we argue that government MPs face stronger political constraints than opposition MPs. This is not a novel proposition (see below) and it should result in lower absence likelihood for government MPs. Theoretically, this is due to the fact that the government is responsible for keeping the chamber quorate (granted, a minor form of constraint) and for safeguarding the passage of the government initiatives, translating into less freedom in terms of absence for government MPs. Empirically, prior research in parliamentary systems found that the government-opposition dimension matters for dissent: being a member of the government side reduces dissent, even overriding policy differences (Willumsen and Öhberg 2017). For absence, the results are similar in a non-parliamentary system: Brown and Goodliffe (2017) studied absence in US state legislatures and found evidence that being part of the majority party decreases absence. Overall, government-opposition absence differences were documented in a non-parliamentary system, and dissent related differences were documented in a parliamentary system, we expand by testing the government-opposition absence difference in a parliamentary system across multiple legislatures. We test the following hypothesis:

$\left(\mathrm{H}_{1}\right)$ Government MPs are less likely to be absent than opposition MPs.

Second, as documented by Rothenberg and Sanders (1999, p. 314), MPs will face different electoral situations and this translates into systematic variation in absence across the election cycle. This would be consistent with multiple mechanisms. Strengthening electoral constraints should influence especially the MPs standing for re-election who return to their constituencies as incumbents. Previously, this incumbency advantage has been shown to be rather small in the United Kingdom (Gaines 1998), but varying among parties (Smith 2013). Overall, this first component would suggest that, in comparison to early stages of the term, absence rates should increase as we approach the next elections.

In addition, political constraints can weaken as well. There is an acknowledgment that MPs will at times be required to be elsewhere than Westminster either for political or personal reasons (Cain, Ferejohn, and Fiorina 1979; Cain, Ferejohn, and Fiorina 1984; Heitshusen, Young, and Wood 2005; Searing 1985). End of term electoral obligations are known to the party, and the party itself benefits from allowing MPs to maximize their reelection chances, and they do have some tools at their disposal. Thus, we test the following hypothesis:

$\left(\mathrm{H}_{2}\right)$ The likelihood of being absent increases as the next elections approach.

However, we do not know whether these electoral constraints influence government and opposition MPs in the same way, or, put it differently, stronger political constraints persist throughout the full electoral cycle for the government MPs. There are several reasons for considering this heterogeneity, as it can also help us better understand government agenda control and internal party discipline. We thus ask the following research question:

(RQ) Are government MP absences affected more by the electoral considerations in comparison to opposition MP absences?

On the one hand, the government has full control over the parliamentary agenda (Döring 1995), hence it is usually able to control when divisions are called, and thus planning can be easier for the government. ${ }^{4}$ To reduce the conflict between having to be present and engage in campaigning, the government can schedule less important and less conflictual divisions towards the end of the legislative term. This consideration is important because it stipulates that, while government MPs

\footnotetext{
${ }^{4}$ Given the presence of Opposition days, they have yet another advantage in terms of planning and concentrated discussion of proposals from the opposition side, which they might want to avoid.
} 
are more constrained, their party can accommodate the constraints if needed, especially when electoral needs require this. Essentially, with the agenda control, the government can coordinate in a way that important legislation will be discussed on days where most of their MPs do not have to be absent for different reasons and make sure that once they have to be absent, the legislation in question is less important. This would imply that government MPs can be freed up once their presence is needed elsewhere, as we approach the upcoming elections.

On the other hand, the literature on legislative business cycles (Brechler and Geršl 2014; Padovano and Gavoille 2017; Lagona and Padovano 2008) suggests that legislative activity (in terms of bills) traditionally increases towards the end of the legislative period to prepare for an election. While a legislative business cycle is present in the United Kingdom, the number of bills introduced and passed declines towards the end of the parliaments. ${ }^{5}$ Furthermore, there are shared electoral constraints, and thus there should be an increase in the absences among opposition MPs as we are approaching the end of the term, because more information about when the election is coming, which generally translates into some increase of absence generated by crystallized electoral constraints. Similarly, there is no systematic evidence that differences in time spent in the constituency provides advantages for opposition $v s$ government MPs. Overall, these components would suggest that, in comparison to early stages of the term, absence rates should increase as we approach the next elections, and this increase should not depend on the MP's government or opposition status.

We will explore these competing possibilities. Overall, we aim to explain absence patterns as a product of constraints related to maximizing the chances of reelection while serving one's party under certain institutional functioning rules. Hence, the strategic use of absence is a set of decisions that aims at balancing these different pressures (or principals), while respecting the day-today structure and schedule imposed through institutional rules. We now introduce our data and the modeling approach that captures these different aspects in a comparative manner.

In this article we study absence in four UK parliaments from 1997-2015. The choice of the United Kingdom as a case has several benefits, but also raises issues about the potential generalizability of the findings. The few existing studies of absence have predominantly been done on electoral systems using first-past-the-post as the United Kingdom does as well, and in that respect the present study is situated as a clear follow-on from these. One element that can limit the generalizability of our findings is the lack of the additional intra-party dynamics: in proportional electoral systems, the signalling from MP to electorate is not necessarily directly linked to a clear, relatively cohesive, geographical unit, and in proportional systems there are usually more candidates running for the same party in the same constituency, which is not the case in the first-past-the-post system of the United Kingdom. In such cases, the interplay between electoral and political constraints could be different, as parties can have additional selection roles, but individual MPs can have different incentives to differentiate themselves from other party members or potential candidates. The difference in the electoral and potential campaign pressures can also influence the amount of effort needed to coordinate potential activities, but yet again, in those cases specific and well-defined constituency work can be more difficult to delimit.

In addition, in the periods covered in this paper the government generally has a comfortable majority in parliament, in the first two periods indeed an extremely comfortable one. This, however, does not mean that the arguments presented here and the results cannot be generalized as absence is a common feature of most parliaments, and all governments have to contend with absence re-

\footnotetext{
${ }^{5}$ Acts and Statutory Instruments: The volume of UK legislation 1950 to 2016. House of Commons Briefing Paper CBP 7438, 21 April 2017.
} 
gardless of its majority. Equally limited focus is dedicated to the idea of pairing, i.e., coordinated absence between government and opposition parties to keep the legislative balance. Anecdotally pairing is used less when there are large majorities, but does exist in some form during all parliaments. Thus, a government with a small majority can still be as secure in its majority if pairing takes place as a government with a large majority.

Overall, the direct link between constituency and MP should make electoral constraints stronger in comparison to other systems, making the United Kingdom a likely place to find larger differences in absence rates when comparing the beginning and the end of a particular legislature. The strength of the parties could make political constraints strong, however, we see comfortable majorities and strong government control, allowing for better planning and potential freedom on the side of the government MPs, potentially weakening these constraints in comparison to other systems, with minority governments or weak coalitions. While these potential differences should be kept in mind, it is unclear whether the case selection could have any systematic implications for the interaction between electoral and political constraints. Our results for many theoretically relevant predictors will be comparable to those reported in the literature, with very few exceptions which we will discuss in detail.

\section{DATA AND METHOD}

\subsection{Variables}

Our analysis includes all divisions voted on in the HoC during four parliaments covering the time period 1997 to 2015. The votes were centralized and made available by The Public Whip project (ThePublicWhip 2015) and our outcome variable is coded as 1 if a particular MP was absent for the vote on a particular division. ${ }^{6}$ When present, independent of the vote choice, the variable is coded to be 0 , and thus for each MP $\times$ division combination we have a valid data entry.

We apply four exclusions based on MP features. First, we omit MPs from Northern Ireland, as we are looking at a subset of MPs who have extremely high absence rates and Northern Ireland has an entirely different party system whose actors did not play a significant role during the period covered in this paper. Second, we exclude MPs who changed parties within one legislature. Those MPs who change parties are suspected of having very different motivations and parliamentary behavior, and this could add an unobserved layer of constraint dynamics specific to these cases. This group is quite small and not enough to test some specific expectations or aid a potentially stronger design. ${ }^{7}$ Furthermore, in terms of behavior, the exact date of switching registered is likely not a strict discontinuity, behavior prior to switching likely reflects some of the considerations behind the switch.

Similarly, we exclude MPs who left the HoC for various reasons, and subsequently there were byelections held in their constituency, and those MPs who joined instead of them. Some by-election cases are due to long-term illness and death, hence prolonged absence is already observed. Some

\footnotetext{
${ }^{6}$ While the literature on selection effects in using parliamentary voting is important (see Carrubba et al. 2006; Hug 2010) this is primarily the case when wishing to estimate a latent dimension through some form of ideal point estimation. In this respect, our aim is to capture who is absent and under what circumstances they are absent and as such the problem of potential bias in the votes becomes less of an issue.

${ }^{7}$ In total, we have $25 \mathrm{MPs}$ who changed parties within one legislature, which includes also those who went independent or first independent and then to another party, or any trajectory essentially. Some of these would have been excluded for other reasons as well, such as 2001 David Burnside and Jeffrey Donaldson who were from Northern Ireland, or 2010 Mark Reckless and Douglas Carswell who triggered a by-election (see next data reduction point).
} 
other MPs end up resigning due to various scandals, but in this case as well, the moment the by-election comes as an end-result or solution we cannot ascertain from which time-point this should influence participatory motivations and behaviors. Finally, we limit our analysis to MPs who were not ministers, also excluding members of the shadow cabinet. ${ }^{8}$ It is expected that they will generally be absent for votes, with clear activities outside the division lobbies.

To test our hypotheses and evaluate our research question, we have two core predictors. First, defined at the division cross-section level, we measure the electoral cycle related differences through the number of (calendar) days remaining until the next election and we reverse this, so that larger numbers reflect more proximity to the upcoming elections. As the four legislatures differ in length, with the two most recent legislatures in our data being five, rather than four years long, in order to remedy potential biases in the estimates of proximity, we apply a minimum-to-maximum rescaling within each legislature for our temporal proximity measure. ${ }^{9}$ Second, defined at the MP level, we code government (1) and opposition (0) status for MPs. From 1997-2010 the opposition MPs are all other MPs than Labour MPs, who are coded as government MPs (previous exclusions apply). For 2010-2015 the opposition MPs are all other MPs than Conservative and Liberal Democrat MPs, who are the government MPs. As described below, we include a multiplicative interaction term of these two variables in our final models to evaluate our research question.

Based on previous findings reviewed above, we include a set of control variables. In order to account for the effects of week days (Noury 2004), we use a nominal variable for the day of the week the division was voted on, with Wednesday as the baseline category. Furthermore, we differentiate between bills proposed by different sides, i.e. government (1) vs opposition (0). At the MP level, we code retirement as a dichotomous variable (1 for retiring next election, 0 otherwise). Those MPs who re-ran for office but lost are not coded as retiring. ${ }^{10}$ Constituency majority reflects the winning margin in the elections preceding the current legislature, expressed in terms of the difference in the percentage of popular votes between the winner and the runner-up in a constituency. ${ }^{11}$ Seniority has been coded as the time elapsed (in years) from the first year an MP entered Parliament based on official MP biographies and the start of the actual legislature analyzed. In most cases, MP seniority entails an unbroken length of service. Where there was a break of service, the first year of entry is used as the basis of the seniority calculation. ${ }^{12}$ Constituency distance from Westminster is driving distance measured in kilometers (through the Google Maps API), with largest local authority in a particular constituency as a starting point and Westminster as an endpoint. ${ }^{13}$

\footnotetext{
${ }^{8}$ We ascertained ministerial roles based on official records of governmental composition and parliamentary records. Ministers are defined as Cabinet Ministers and Ministers of State who are allowed to attend Cabinet. We refitted our models by including a control for ministers and for by-election entries and exits, and our results do not change. Unsurprisingly, for example, the minister dummy is associated with a large positive effect on absence probability.

${ }^{9}$ Our results are unchanged if we count remaining days with sessions held.

${ }^{10} \mathrm{We}$ are not concerned with when an MP announces her retirement (see Willumsen and Goetz 2017), but the notion that they do not run for reelection and have entered a potentially disengaging career stage (Bailer and Ohmura 2018), no longer suffering from an electoral constraint. It is also likely that the timing of announcement of retirement is not equal to when the actual decision was made and when the potential impact began.

${ }^{11}$ Constituency majority figures are from "The British Parliamentary Constituency Database, 1992-2005, Release 1.3" (Norris 2005) and the "May 6th 2010 British General Election Constituency Results Release 5.0” (Norris 2010).

${ }^{12}$ For example, Sir Peter Tapsell represented Nottingham West from 1959 until losing his seat at the 1964 election. He re-entered parliament at the 1966 election for what is now Louth and Horncastle. In this case, his seniority would be calculated from taking his first year of entry as 1959.

${ }^{13}$ We chose the starting point because even if MPs take the train, it is likely that they will do it from the larger towns or cities. It is not known how MPs get to Westminster, but even if there are minor differences between driving distance and distance for the train or plane for that matter, we believe there is no systematic bias given by constituency.
} 
We list descriptive statistics for our predictors in Online SI A1. As with our core predictor of election proximity, for the multivariate models we rescale all continuous predictors (constituency majority, seniority and distance) to range from their minimum (0) to their maximum (1) and these are carried out as within-legislature rescaling. While for seniority and distance this should matter less, for constituency majority this could be more important as the electoral results and margins varied quite a lot between the elections analyzed here.

\subsection{Modeling}

In total, we analyze 5033 divisions and the behavior of 1035 MPs. As many MPs are present in multiple legislatures, but there are context and potentially role related differences, we will treat them as separate instances across different legislatures. This step also assures that we are not conflating within- and between-MP differences when it comes to MP specific features. We will return to alternative grouping, within-MP models, and legislature specific models later on. This results in 2173 observations at the MP level; detailed sample size breakdowns are reported in Online SI A1.

Since we observe the same MPs behavior across many divisions, we treat absence as a division specific quantity that is nested within MPs. As our outcome variable is dichotomous, we fit binomial models with a logit link function estimated via Restricted Maximum Likelihood, modeling directly the probability of absence $v s$ presence. In the first step, we fit the models to all four legislatures, and thus we include legislature fixed effects.

Prior to our final, most complex model, we report several more reduced models in order to compare model fit and also show the robustness of our core findings. In our final model, we model the between-MP variation of the electoral cycle effect as a function of the government $v s$ opposition status, resulting in a cross-level interaction. In this case, rather than change in predicted absence or presence, we aim at systematically reducing the unexplained variation in why for some MPs the electoral cycle could matter more for their decisions.

We extend our core analysis with a set of robustness checks and then discuss legislature specific models and within-MP trajectories for the subset of cases where there was a change in oppositiongovernment status at the 2010 elections. These models will be reviewed when discussing the findings in the next section.

\section{Results}

\subsection{Absence in the 1997-2015 period}

The first step in our analysis is to have a descriptive look at the absence patterns in our data. To this end, we display MP level absences Figure 1. On average, most MPs are more likely to be present than absent ( 0.31 overall absence proportion), and on most days, the average presence is well above 50\%, with substantial variation. The between-MP variation amounts to $13 \%$ of the total variation (on average), which suggests that while division specific variation is still the largest component in all legislatures covered here, it can only tell a partial story of absences in the HoC.

[Figure 1 around here]

Moving beyond descriptive analyses, Table 1 lists the core model results. There are two main takeaways from this table. Considering both the AIC and BIC we observe a decrease in model 
misfit as we increase the complexity of our model. ${ }^{14}$ In this regard, while not included in this table, we also compared our final model to one with all components except the interaction and we see that our model fits best and significantly better. ${ }^{15}$ Second, we see overall consistency of the effect sizes across specifications. While the electoral cycle's effect decreases with additional controls, the difference between government and opposition members is estimated to be larger as we control for the set of covariates indicated by the literature.

\section{[Table 1 around here]}

We concentrate on the findings pertaining our hypotheses and research question, with full model results reported in Online SI A2. All the control variables indicate effects in the directions expected based on the previous literature. One potential exception is that we find no significant effect for constituency majority, i.e. those with a larger majority behind them are not necessarily more absent. It could be that the measurement is too crude, and information regarding standing in the polling for example might be more suitable to evaluate this electoral motivation better, although this would be at party level and not for each individual MP. In order to make sure that our results are not driven by this measurement issue, we have specified an alternative model where we coded constituencies whether they were listed as marginal by BBC or the Guardian, but our results are unchanged. Building on Bernecker (2014) we also evaluated if there is any opposition or government specific effect regarding the constituency majority, and found no heterogeneity when looking at the full data and no indications that the political and electoral constraint interplay would be dependent on the constituency majority. However, it is important to note that in our main analysis, we use all MPs, both re-running ones and retiring ones. As displayed in the robustness checks later on, for only re-running MPs, we already see a much stronger effect, in contrast to those not re-running (essentially null to negative effects). Once we further restrict our models and look at the MPs across legislature models (there is a within-MP component), we find the expected effect where higher constituency majority indicates higher absence probability, i.e. safety turns into less effort in the parliament. Thus, what we can see is that constituency majority can be linked to parliamentary effort, but mostly matters for re-running MPs.

Our general understanding of the government-opposition divide in parliamentary systems with governments being the agenda setters is in line with our finding that government MPs are much less likely to be absent than those from the opposition benches $\left(\mathrm{H}_{1}\right)$. We also see that once the election is approaching absences become more frequent, consistent with the explanations introduced earlier focusing on the campaign efforts needed and the potentially lower salience legislation left towards the end of the cycle $\left(\mathrm{H}_{2}\right)$. However, the overall magnitude of this is effect is comparatively smaller.

[Figure 2 around here]

In Figure 2 we display how these constraints interact and how these are balanced (RQ). The difference between opposition and government MP absence likelihood is decreasing as we get closer and closer to the upcoming elections. The effect is statistically significant and in substantive terms we go from a difference in absence probability of 0.113 to 0.086 , which is a $23 \%$ reduction. Both opposition and government MPs are more absent as elections get closer, but this change is close to 50\% larger for government MPs. The differences between the start and the end of legislature are 0.038 and 0.065 on the probability scale, which are quite small.

\footnotetext{
${ }^{14}$ Likelihood based model fit comparisons indicate significant model misfit reduction at each step.

${ }^{15} \mathrm{AIC}$ is 2936480 and BIC is 2936711 for a model with all controls, but without the interaction between electoral cycle and government. This is significantly worse fitting than our full model, including the interaction $\left(\chi^{2}=38.236, p<0.001\right)$.
} 


\subsection{Robustness checks}

We present results from four models in Table 2, with full list of coefficients reported in Online SI A2. In the first two models, we zoom in at potential specificity regarding whether the MPs stood for reelection. Instead of a more complex three-way interaction, we fit our models separately for retiring and non-retiring MPs. Our core results and opposition-government differences in the electoral cycle effect are consistent with our main results.

\section{[Table 2 around here]}

We argued that, especially in Westminster systems, government MPs face stronger political constraints, hence their absence rates will be lower. However, the opposition is usually a more heterogeneous block and there might be within-block differences in how parties control their MPs. Looking at our data, we see that MPs of smaller parties are more frequently absent in comparison to their opposition colleagues who are members of either of the three larger parties. The third model shows though that this has no influence on our results: focusing on Labour, Conservative, and Liberal Democrat MPs only, our substantive findings are unchanged.

Finally, the fourth model relaxes the assumption of independence of MPs as grouping units between legislatures, i.e. an MP in multiple legislatures will stay the same grouping unit, reducing our second level sample size to 1035, the number of unique MPs across all four legislatures. This means that many predictors previously considered second-level predictors (invariant within nesting unit) will vary now, however our core results are unchanged. ${ }^{16}$

\subsection{Separate legislatures}

So far, we have seen consistent evidence for some heterogeneity in the effect of political constraints throughout the electoral cycle. However, there are systematic differences in average absence rates between legislatures, with 1997-2001 having the highest average absence rates and 2005 to 2015 period seeing more MPs being present. While we account for these differences through the inclusion of legislature fixed effects, the legislatures themselves come with different political realities and power balances. Hence, we refit our main model (sans legislature fixed effects) for each legislature separately. ${ }^{17}$

[Figure 3 around here]

Figure 3 summarizes our results while full model results are reported in Online SI A2. In the 2001-2005 and 2010-2015 sessions the government to opposition convergence operates in the direction of government MPs catching up to the opposition MP absence rates. We can fit a straight line within the uncertainty bounds for opposition MPs, thus their behavior seems to be mostly unchanged throughout these legislatures. These are results from two legislatures that had governments of different political persuasions (1) and there was institutional change in between them (2), as in the second legislature MPs could be certain when the end of parliament would be after the introduction of the Fixed-term Parliaments Act.

On the other hand, the 1997-2001 and 2005-2010 legislatures support a scenario with parallel opposition and government absence development: strengthening electoral constraints, acted uniformly, both opposition and government MPs being more absent towards the end of the term. It

\footnotetext{
${ }^{16}$ Regarding the control variables, in this specification the effect of seniority is substantially larger and the previously not significant constituency majority positive effect is now significant, but still quite small.

${ }^{17}$ Alternatively, we can add the legislature identifier variables to the interaction, generating a three-way interaction and some additional two-way interactions. Fitting that model, our results are identical.
} 
is noteworthy that opposition MPs are still more likely to be absent than their government counterparts. In both legislatures, the starting differences (beginning of term) are quite large and stay constant, accumulating absences over time.

We found no readily available common features shared by both of these legislatures that could explain why the government agenda setting asymmetry (second facet of constraints) does not appear to be a factor here. We have looked at non-linearity, but we did not identify major break points or strong non-linearity in most of the cases analyzed here. Including this level of complexity in the hierarchical models will not come with significant increase in fit. ${ }^{18}$

The 1997-2001 legislature saw a government with a very large majority and with the largest proportion of new MPs since 1945. It could be possible that this meant these new MPs were in the exploring phase of their parliamentary life (Bailer and Ohmura 2018). While we do not have pre1997 data in our analysis, we looked at opposition MPs in the 1997-2001 legislature and compared new MPs with those who have had been in the HoC before. If anything, we have found a steeper slope for opposition MPs who were not newcomers in the 1997-2001 legislature, although the difference compared to newcomers was not statistically significant. Furthermore, we analyzed opposition MPs present both in the 2001-2005 and 2005-2010 legislatures, and indeed, their absence trajectories change from no electoral cycle sensitivity to large increases in absence. Furthermore, in the 2005-2010 legislature, new opposition MPs and those who have been in the HoC for the 2005-2010 legislature have very similar absence behavior.

While the trajectories, or differences in them, cannot be directly explained by the size of the majority, one insight is quite clear from our analysis: larger majority sizes (such as in the first two legislatures analyzed here) allow, on average, more government MPs to be absent. Government MP absence rates in the beginning of the large majority legislatures are as high as the (government) absence rates will go right in the election campaigns in smaller majority legislatures (after 2005). Opposition absences and their trajectories are less responsive to the majority sizes, with the exception of the very large majority in the 1997-2001, where opposition absences were the largest.

Thus, our overall findings indicating some interaction between political and electoral constraints are composed of two markedly different patterns: in two of the legislatures we see that opposition absence rates are mostly unchanged while government absence rates increase, whereas in the remaining two legislatures these trajectories are parallel. Combined, these result in an overall smaller increase of absence for opposition MPs than for government MPs, who are always increasing their absences with the new elections approaching.

\subsection{Within-MP trajectories}

In order to gain additional insights, we look at MPs who changed status in between legislatures, specifically 2005-2010 and 2010-2015 legislatures, which went from a Labour government to a Conservative \& Liberal Democrat government. We subset our data to all MPs who were part of both legislatures, did not hold any ministerial positions and did not retire after either of the legislatures, MPs standing for re-election in 2015 as well. We exclude retiring MPs from this analysis to be consistent with the presence of potential electoral incentives. Thus, we have two groups of MPs: the Labour MPs who went from a government side to the opposition (103), and Conservative \& Liberal Democrat MPs who went from opposition side to government (113).

\footnotetext{
${ }^{18}$ Noteworthy, for the 1997-2001 legislature, accounting for the non-linearity indicates a flattening out of opposition absence increase towards the end of the session, but this is not something that we see in the other legislature.
} 
We combine the two parliaments for each of these groups and fit a hierarchical model of absence where, as before, divisions are nested within MPs. However, the difference is that we are interested in the trajectories throughout time including the switch between the parliaments. We follow Singer and Willett (2003) in terms of parametrization and model building. For both groups of MPs, the best fitting final models estimate a varying starting point for absence probability at the beginning of the 2005-2010 parliament, varying change in the elevation when transitioning to the 2010-2015 legislation, and two varying trajectories. ${ }^{19}$ We report the summary of the average trajectories in Figure 4.

\section{[Figure 4 around here]}

We largely reproduce the substantive findings from the cross-sectional time related analysis. Going from government to opposition we see that MPs (Labour MPs in both parliaments) were on average much less absent when they were in government and there is a sharp increase in their absence rates once they start their tenure as opposition members. This is very much in line with the notion that it is the government of the day who is responsible for having a majority in the HoC and the opposition MPs can therefore be more absent. Most importantly, however, we see that while they were in government the absence rates increased towards the end of the parliamentary term, but this is not the case for when the same MPs were in opposition. Going from opposition to government, we see a very substantial drop in absence likelihood, however no change trajectory differences: Conservative and Liberal Democrat MPs in the 2005-2010 opposition were quite sensitive to the electoral cycle as well. They essentially reach the same absence probability at the end of the electoral cycle of their government tenure as they had at the beginning of their opposition period.

\section{[Figure 5 around here]}

In Figure 5 we summarize an extended version of the "From opposition to government" model, where each time related varying slope (including the switch to second legislature) has one predictor, namely the party the MP was a member of. In other words, we estimated three cross-level interactions. Once uncertainty is incorporated, we find no statistically significant differences between Conservative and Liberal Democrat MP behaviour. This also indicates that our results are not driven by one of these parties, when focusing on the "From opposition to government" transition. However, in opposition, Liberal Democrats were less likely to be absent in comparison to Conservatives, but this changes in government, especially as the 2015 elections are getting closer. Furthermore, the electoral constraints appear to be stronger (steeper slope) for Liberal Democrats in government when compared to the Conservative MPs. It is, however, important to keep in mind that for the Liberal Democrats government participation has so far been a one-off experience. Although if coalition government is to occur again, then the experience of the Liberal Democrats as a junior coalition partner is relevant for understanding the behavior of their MPs.

\section{Discussion AND CONCLUSIONS}

In the four parliaments between 1997 and 2015, we have looked at absences across 5033 divisions for over 500 individual MPs in each parliament. The average share of absences is $31 \%$, indicating that while MPs are mostly present, a non-trivial share of parliamentary vote participation is avoided. More importantly, this ranges from 5\% to 99\% between MPs, revealing substantial variation of absenteeism. These raw numbers suggest that absence is part of the parliamentary

\footnotetext{
${ }^{19}$ More precisely, we estimate a general trajectory and change in the slope in the second parliament.
} 
reality, and systematic differences depending on when the vote is being held, and who is participating need to be considered if we want to understand accountability, parliamentary work, and functioning of parliaments in democratic parliamentary systems.

The inherent assumption, at times clearly stated, is that absence for the most part is not relevant for position-taking and is just a matter of "simple" absences. We have shown though that there are systematic factors that can account for why MPs decide not to participate in a division, and these are in line with broader theories of legislator behavior. Thus, absences might be "simple", but they are quite systematic. Furthermore, changing patterns of absence or the use of this tool can help us better understand some broader dynamics of legislative activity.

It is important to stress that the decision to be absent from vote is taken by the individual MPs. Unfortunately, we have no way of monitoring their decision-making process of being present or absent. Anthropological studies of the MPs and their actions in parliament (see Crewe 2015) suggest that the pressure on MPs comes from multiple sides and to pinpoint one exact reason for a decision to be absent can be near impossible. However, our approach does capture the multifaceted nature of this pressure and by examining the various constraints that MPs face and how they might balance these it is possible to establish part of the process that makes or allows MPs to decide to absent themselves from divisions. However, we believe that by examining the various constraints that MPs face and how they might balance these it is possible to establish part of the process that makes or allows MPs to decide to absent themselves from divisions. The impact of some of these constraints are exactly as one would expect or has been documented in other systems.

Most importantly, our findings speak to how the government carries out its responsibility to ensure they have a majority in a division and how this influences what their MPs can do, especially when reelection pressures are looming. Overall, we show that the absence probabilities among government MPs are lower than opposition MPs throughout the life cycle of the particular parliament. Furthermore, as the next elections are getting closer, absences are on the rise, on average. However, this rise happens at different rates for government and opposition MPs. This is likely due to a mixture of loosening political constraints associated with the type of legislation the government proposes and electoral constraints the MPs are facing. On average, these conditions have a stronger influence on government MPs who are usually present at a high rate in the beginning of the term.

However, this general, overall result is driven by somewhat divergent results once we focus on each legislature separately. In 2001-2005 and 2010-2015, opposition MPs have constant absence rates, with government MPs catching up by the end of the legislature. In the remaining two legislatures, government and opposition MPs absence rates increase hand-in-hand. Accordingly, the answer to our research question is mixed, which highlights the need to consider more specific political realities and political power constellation when we study absences. A possible explanation for this relates to the strength of majority and belief in electoral success. While the 1997-2001 parliament was characterized by Labour having won their strongest mandate, there had been political developments during the term which meant that the government did not take another victory for granted (Harrop 2001, p. 295) and with the majority had the possibility of allowing more MPs to be absent for campaigning. This should lead to a reaction from opposition MPs to focus on the campaign earlier and therefore also increase their absence.

Some of the systematic differences might be party related, and further research should consider those aspects more in detail. As we have shown, a comfortably sizeable majority offers more 
freedom overall to government MPs, with the within legislature trajectory of growing absences being identical across different legislatures. However, opposition behavior is less well aligned with these differences in majority sizes, which indicates that it is unclear how opposition MPs are influenced by government MP behavior or how expectations regarding government MP behavior translate into decisions within the ranks of the opposition. We believe this to be an exciting avenue for future research regarding opposition behavior in parliaments. Overall, more studies of these two legislatures will be needed in order to better understand why the opposition behavior was different and how this can be related to pairing, party discipline, or various other factors.

Conceptualizing absence as part of the parliamentary toolbox also means that informal, or not measurable, parliamentary practices can underlie or overwrite the use of this tool. Most notably, the possibility that pairing can render a different picture of absence. While paired absence would still result in limited information that voters can acquire regarding position taking of their MP, the potential push back against political constraints is less worrisome. Tolerated and calculated paired absence, or the possibility to be paired and find a pair, would be a function of expected division related features. In addition, our findings offer a fertile ground for further exploiting variation in the use of absence in two areas: individual MP learning behavior throughout ones career in how to adequately use these absence or how to correct for them if necessary, but also in close relationship to the rebellion literature (Campbell and Cowley 2014; Wagner, Vivyan, and Glinitzer 2020), discussing avenues for communicating and motivating absences towards interested and impacted stakeholders.

Finally, we do not know whether MPs actually spend the time in their constituency when they are not present. We conceptualized the absence decision as weighing some costs and benefits between presence at these two places, which is also in line with self-reported MP experiences (Crewe 2015), and with previous work by Norris (1997) and Rush and Giddings (2011). However, we did not test the strict dichotomy between constituency work or parliamentary work. There is strong evidence that constituency work, whether physically in the constituency or case work for constituents, has increased over the past decades and that focus on constituency matters is what constituents want the MP to focus on (Campbell and Lovenduski 2015). Empirically, this relationship has been found through several approaches, from survey experiments (Vivyan and Wagner 2016) to questions posed (Kellermann 2016), and recently on spending on constituency surgeries and early day motions (Parker 2021). The strong focus on constituency appears to be continuing even when MPs have decided to retire (Willumsen and Goetz 2017). This evidence suggests that where MPs are rational in their decision-making the electoral constraints provided by the constituency should be important for their choice of activity. However, MPs can have other arrangements, from private sector jobs to consultancy and other activities which might result in taking time away from their parliamentary activities. Geys (2013) found evidence that an election cycle exists in whether MPs having paid outside interests depending on seat security and the decision to run for re-election, and there is evidence for a connection between earnings and parliamentary activity (Geys and Mause 2012). These features are interrelated with the potential constituency vote margin and seat security (Bernecker 2014), however recent work by Weschle (2021) builds on an extensive new dataset and shows that, while counterintuitive, moonlighting has an effect on MPs' parliamentary effort by increasing presence and voting activity, for Conservative MPs who hold private sector jobs. Accordingly, future research is needed to devise more precise measures of the MP activities outside of the parliament, linking public appearances and scheduled activities to the parliamentary agenda to explore how MPs balance the constraints more in detail. 
The findings in this article are naturally constrained by being from a first-past-the-post system and it is possible that in countries with an even stronger control of nomination, for instance national party lists, we would see a much stronger relationship in terms of political constraints and electoral constraints mixing. This would mean a stronger party control manifesting itself as lasting political constraint: less freedom or motivation for MPs to be absent and rather dedicating their time to parliamentary activity to please the party principals. However, we can also hypothesize the opposite in proportional systems with local control of nominations. The impact of coalition governments, be they minority or majority coalitions, also needs to be considered, and potentially change the dynamics in the constraints facing MPs. The present paper only has one period of coalition governments included, thus future research should consider the use of absence within coalition governments.

Overall, working on the House of Commons allowed us to extend previous findings from the US case in a context where one of the core components is different because we have stronger parties. Exploring the role of government agenda control on absences in parliaments with larger single majorities and then coalition governments, while keeping other factors constant, is a further benefit for a more overarching understanding of how absence might be strategically used to navigate between different principals and constraints. Furthermore, our findings have important implications for disentangling legislative activity throughout an electoral cycle, where indeed, absence can be used strategically, but this happens predominantly in ways that will not jeopardize the government majority, rather it can allow MPs to engage in other activities, with the help of the governments agenda-control capabilities and the party sanctioning such plans.

\section{REFERENCES}

Amacher, R. C. \& Boyes, W. J. (1978). Cycles in senatorial voting behavior: Implications for the optimal frequency of elections. Public Choice 33(3), 5-13.

Arnold, R. D. (1992). The logic of congressional action. Yale University Press.

Bailer, S. \& Ohmura, T. (2018). Exploring, maintaining, and disengaging: The three phases of a legislator's life. Legislative Studies Quarterly 43(3), 493-520.

Barro, R. J. (1973). The control of politicians: An economic model. Public Choice, 19-42.

Benedetto, G. \& Hix, S. (2007). The rejected, the ejected, and the dejected: Explaining government rebels in the 2001-2005 British House of Commons. Comparative Political Studies 40(7), 755781.

Bernecker, A. (2014). Do politicians shirk when reelection is certain? Evidence from the German parliament. European Journal of Political Economy 36, 55-70.

Besley, T. \& Larcinese, V. (2011). Working or shirking? Expenses and attendance in the UK Parliament. Public Choice 146(3-4), 291-317.

Brechler, J. \& Geršl, A. (2014). Political legislation cycle in the Czech Republic. Constitutional Political Economy 25(2), 137-153.

Brown, A. R. \& Goodliffe, J. (2017). Why do legislators skip votes? Position taking versus policy influence. Political Behavior 39(2), 425-455.

Buchanan, J. M. \& Tullock, G. (1965). The calculus of consent: Logical foundations of constitutional democracy. University of Michigan press.

Cain, B. E., Ferejohn, J. A., \& Fiorina, M. P. (1979). The house is not a home: British MPs in their constituencies. Legislative Studies Quarterly 4(4), 501-523.

- (1984). The constituency service basis of the personal vote for US representatives and British members of parliament. American Political Science Review 78(1), 110-125. 
Campbell, R. \& Cowley, P. (2014). Rebellion versus Loyalty, Shirking versus Working: A note on framing parliamentary behaviour. Representation 50(4), 421-427.

Campbell, R. \& Lovenduski, J. (2015). What should MPs do? Public and parliamentarians' views compared. Parliamentary Affairs 68(4), 690-708.

Campbell, R. et al. (2019). Legislator dissent as a valence signal. British Journal of Political Science $49(1), 105-128$.

Carey, J. M. (2007). Competing principals, political institutions, and party unity in legislative voting. American Journal of Political Science 51(1), 92-107.

Carrubba, C.J. et al. (2006). Off the record: Unrecorded legislative votes, selection bias and roll-call vote analysis. British Journal of Political Science 36(4), 691-704.

Cohen, L. R. \& Noll, R. G. (1991). How to vote, whether to vote: Strategies for voting and abstaining on congressional roll calls. Political Behavior 13(2), 97-127.

Cowley, P. (2002). Revolts and rebellions: Parliamentary voting under Blair. Politico's.

Crewe, E. (2015). The House of Commons: An anthropology of MPs at work. Bloomsbury Publishing.

Donnelly, C. P. (2019). Yea or Nay: Do legislators benefit by voting against their party? Legislative Studies Quarterly 44(3), 421-453.

Döring, H. (1995). Time as a scarce resource: Government control of the agenda. Parliaments and majority rule in Western Europe. Ed. by H. Döring. Campus Frankfurt/St Martin's Press, 223-46.

Dougan, W. R. \& Munger, M. C. (1989). The rationality of ideology. The Journal of Law and Economics 32(1), 119-142.

Downs, A. (1957). An economic theory of democracy. Harper New York.

Fenno, R. F. (1977). US House members in their constituencies: An exploration. American Political Science Review 71(03), 883-917.

Fisher, J. et al. (2014). You get what you (don't) pay for: The impact of volunteer labour and candidate spending at the 2010 British General Election. Parliamentary Affairs 67(4), 804-824.

Fisher, J. et al. (2016). Is all campaigning equally positive? The impact of district level campaigning on voter turnout at the 2010 British general election. Party Politics 22(2), 215-226.

Forgette, R. \& Sala, B. R. (1999). Conditional party government and member turnout on Senate recorded votes. The Journal of Politics 61(2), 467-484.

Fortunato, D. \& Provins, T. (2017). Compensation, opportunity, and information: A comparative analysis of legislative nonresponse in the American States. Political Research Quarterly 70(3), 644-656.

Gaines, B. J. (1998). The impersonal vote? Constituency service and incumbency advantage in British elections, 1950-92. Legislative Studies Quarterly 23(2), 167-195.

Geys, B. (2013). Election cycles in MPs' outside interests? The UK House of Commons, 20052010. Political Studies 61(2), 462-472.

Geys, B. \& Mause, K. (2012). Delegation, accountability and legislator moonlighting: Agency problems in Germany. German Politics 21(3), 255-273.

- (2016). The limits of electoral control: Evidence from last-term politicians. Legislative Studies Quarterly 41(4), 873-898.

Harrop, M. (2001). An apathetic landslide: The British general election of 2001. Government and Opposition 36(3), 295-313.

Hart, D. B. \& Munger, M. C. (1989). Declining electoral competitiveness in the House of Representatives: The differential impact of improved transportation technology. Public Choice 61(3), 217-228.

Heitshusen, V., Young, G., \& Wood, D. M. (2005). Electoral context and MP constituency focus in Australia, Canada, Ireland, New Zealand, and the United Kingdom. American Journal of Political Science 49(1), 32-45. 
Hix, S. \& Noury, A. (2016). Government-opposition or left-right? The institutional determinants of voting in legislatures. Political Science Research Methods 4(2), 249-73.

Hug, S. (2010). Selection effects in roll call votes. British Journal of Political Science 40(1), 225-235. Johnston, R. et al. (2002). Voting in the House or wooing the voters at home: Labour MPs and the 2001 general election campaign. Journal of Legislative Studies 8(2), 9-22.

Jones, D. R. (2003). Position taking and position avoidance in the US Senate. Journal of Politics 65(3), 851-863.

Kam, C. J. (2009). Party discipline and parliamentary politics. Cambridge University Press.

Kellermann, M. (2016). Electoral vulnerability, constituency focus, and parliamentary questions in the House of Commons. The British Journal of Politics and International Relations 18(1), 90106.

Lagona, F. \& Padovano, F. (2008). The political legislation cycle. Public Choice 134(3-4), 201-229.

Longley, N. (2003). Modelling the legislator as an agent for the party: The effects of strict party discipline on legislator voting behaviour. Contemporary Economic Policy 21, 490-499.

Lott, J. R. (1987). Political cheating. Public Choice 52(2), 169-186.

- (1990). Attendance rates, political shirking, and the effect of post-elective office employment. Economic Inquiry 28(1), 133-150.

Norris, P. (1997). The puzzle of constituency service. The Journal of Legislative Studies 3(2), 29-49.

- (2005). The British Parliamentary Constituency Database, 1992-2005, Release 1.3.

- (2010). May 6th 2010 British General Election Constituency Results Release 5.0.

Noury, A. G. (2004). Abstention in daylight: Strategic calculus of voting in the European Parliament. Public Choice 212, 179-211.

Olson, M. (1965). The logic of collective action. Cambridge: Harvard University Press.

Padovano, F. \& Gavoille, N. (2017). Legislative cycles in a semipresidential system. Journal of Institutional and Theoretical Economics 173(3), 470-497.

Parker, D. C. (2021). Looking after constituency interests: The utilisation of MP expenses and Early Day Motions to craft constituency service home styles. Parliamentary Affairs 74(1), 158179.

Riker, W. H. \& Ordeshook, P. C. (1968). A theory of the calculus of voting. American Political Science Review 62(1), 25-42.

Rosas, G. \& Shomer, Y. (2008). Models of nonresponse in legislative politics. Legislative Studies Quarterly 33(4), 573-601.

Rosas, G., Shomer, Y., \& Haptonstahl, S. R. (2015). No news is news: Nonignorable nonresponse in roll-call data analysis. American Journal of Political Science 59(2), 511-528.

Rothenberg, L. S. \& Sanders, M. S. (1999). Rational abstention and the congressional vote choice. Economics \& Politics 11(3), 311-340.

Rush, M. \& Giddings, P. (2011). Parliamentary socialisation. Parliamentary Socialisation. Springer, 174-194.

Searing, D. D. (1985). The role of the good constituency member and the practice of representation in Great Britain. The Journal of Politics 47(2), 348-381.

Singer, J. D. \& Willett, J. B. (2003). Applied longitudinal data analysis: Modeling change and event occurrence. Oxford University Press.

Slapin, J. B. et al. (2018). Ideology, grandstanding, and strategic party disloyalty in the British Parliament. American Political Science Review 112(1), 15-30.

Smith, T. H. (2013). Are you sitting comfortably? Estimating incumbency advantage in the UK: 1983-2010-A research note. Electoral Studies 32(1), 167-173.

Spirling, A. \& McLean, I. (2007). UK OC OK? Interpreting optimal classification scores for the UK House of Commons. Political Analysis 15(1), 85-96. 
Spirling, A. \& Quinn, K. (2010). Identifying intraparty voting blocs in the UK House of Commons. Journal of the American Statistical Association 105(490), 447-457.

Staats, E. B. (1988). Public service and the public interest. Public Administration Review 48(2), 60105.

ThePublicWhip (2015). Votematrix for House of Commons, 1997-2015.

Vivyan, N. \& Wagner, M. (2016). House or home? Constituent preferences over legislator effort allocation. European Journal of Political Research 55(1), 81-99.

Wagner, M., Vivyan, N., \& Glinitzer, K. (2020). Costly signals: Voter responses to parliamentary dissent in Austria, Britain, and Germany. Legislative Studies Quarterly 45(4), 645-678.

Weschle, S. (2021). Do Politicians' Private Sector Jobs Affect Their Parliamentary Activity? Working paper, 000-000.

Whiteley, P. F. \& Seyd, P. (1994). Local party campaigning and electoral mobilization in Britain. The Journal of Politics 56(1), 242-252.

- (2003). How to win a landslide by really trying: the effects of local campaigning on voting in the 1997 British general election. Electoral Studies 22(2), 301-324.

Willumsen, D. M. (2019). So far away from me? The effect of geographical distance on representation. West European Politics 42(3), 645-669.

Willumsen, D. M. \& Goetz, K. H. (2017). Set free? Impending retirement and legislative behaviour in the UK. Parliamentary Affairs 70(2), 254-279.

Willumsen, D. M. \& Öhberg, P. (2017). Toe the line, break the whip: Explaining floor dissent in parliamentary democracies. West European Politics 40(4), 688-716.

Zupan, M. A. (1991). Local benefit-seeking and national policymaking: Democrats vs. Republicans in the legislature. Public Choice 68, 245-258. 


\section{TAbles}

Table 1: Hierarchical models of absence probability

\begin{tabular}{|c|c|c|c|c|c|c|}
\hline & Baseline & Core predictors & Varying slope & With interaction & Legislature fixed effects & All controls \\
\hline Elect cycle & & $0.428(0.005)^{* * *}$ & $0.456(0.019)^{* *}$ & * $\quad 0.299(0.030)^{* * *}$ & $0.299(0.030)^{* * *}$ & $0.191(0.032)^{* * *}$ \\
\hline Govt. $\times$ cycle & & & & $0.250(0.038)^{* * *}$ & $0.249(0.038)^{* * *}$ & $0.262(0.041)^{* * *}$ \\
\hline AIC & 3163349 & 3155000 & 3131408 & 3131371 & 3131188 & 2936443 \\
\hline $\mathrm{BIC}$ & 3163374 & 3155052 & 3131485 & 3131461 & 3131316 & 2936687 \\
\hline MPs & 2173 & 2173 & 2173 & 2173 & 2173 & 2173 \\
\hline (Var) MPs & 0.488 & 0.417 & 0.558 & 0.557 & 0.495 & 0.496 \\
\hline (Var) Slope & & & 0.756 & 0.741 & 0.741 & 0.844 \\
\hline (Cov) (Int, Slope) & & & -0.315 & -0.310 & -0.279 & -0.313 \\
\hline
\end{tabular}

Notes: (Restricted) Maximum Likelihood estimates of logit coefficients. Standard errors in parentheses, ${ }^{* * *} p<0.001 ;{ }^{* *} p<0.01 ;{ }^{*} p<0.05$. 
Table 2: Summary of robustness checks

\begin{tabular}{lcrrr}
\hline & Non-retiring only & \multicolumn{1}{c}{ Retiring only } & Three main parties & \multicolumn{1}{c}{ MPs across legs. } \\
\hline Intercept & $-0.866(0.041)^{* * *}$ & $-0.623(0.132)^{* * * *}$ & $-0.893(0.038)^{* * *}$ & $-1.088(0.022)^{* * *}$ \\
Elect. cycle & $0.113(0.032)^{* * *}$ & $0.586(0.105)^{* * *}$ & $0.177(0.032)^{* * * *}$ & $0.269(0.026)^{* * *}$ \\
Gvt. MP & $-0.690(0.035)^{* * *}$ & $-0.866(0.087)^{* * *}$ & $-0.685(0.032)^{* * *}$ & $-0.611(0.010)^{* * * *}$ \\
Govt. $\times$ cycle & $0.265(0.040)^{* * *}$ & $0.278(0.134)^{*}$ & $0.276(0.040)^{* * *}$ & $0.265(0.016)^{* * *}$ \\
Legislature FE & Yes & Yes & Yes & Yes \\
All controls & Yes & Yes & Yes & Yes \\
\hline AIC & 2438321 & 497791 & 2877844 & 2983550 \\
BIC & 2438549 & 497989 & 2878087 & 2983794 \\
Division $\times$ MP & 2286514 & 448107 & 2681668 & 2734621 \\
MPs & 1818 & 355 & 2131 & 1035 \\
(Var) MPs & 0.476 & 0.561 & 0.466 & 0.335 \\
(Var) Cycle slope & 0.678 & 1.529 & 0.828 & 0.593 \\
(Cov) (Int, slope) & -0.296 & -0.328 & -0.305 & -0.152 \\
\hline
\end{tabular}

Notes: (Restricted) Maximum Likelihood estimates of logit coefficients. Standard errors in parentheses. ${ }^{* * *} p<0.001 ;{ }^{* *} p<0.01 ;{ }^{*} p<0.05$ 


\section{FIGURES}

Figure 1: Descriptive summary

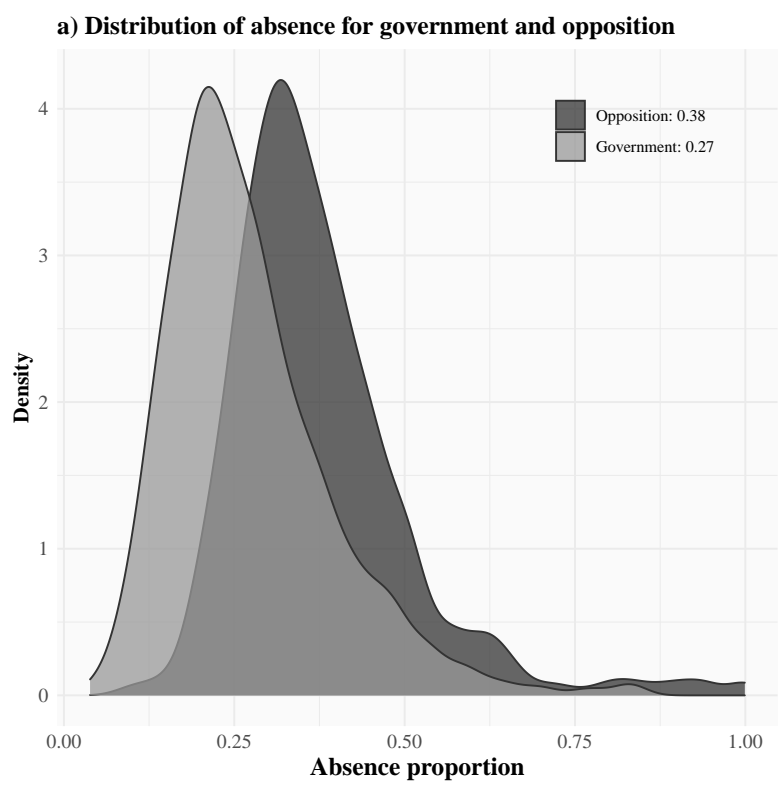

b) Absence throughout the legislative term

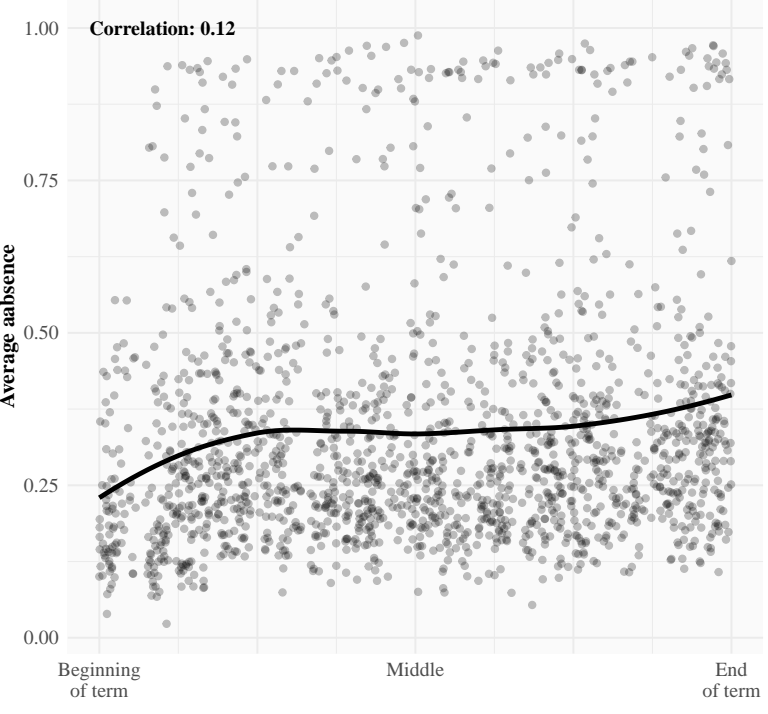

Notes: Panel a) is a density plot, with averages for each type of MP displayed as well. Panel b) is a scatter plot with LOESS line overlaid and bivariate Pearson's correlation displayed. 
Figure 2: Absence probability as a function of electoral cycle for opposition and government MPs

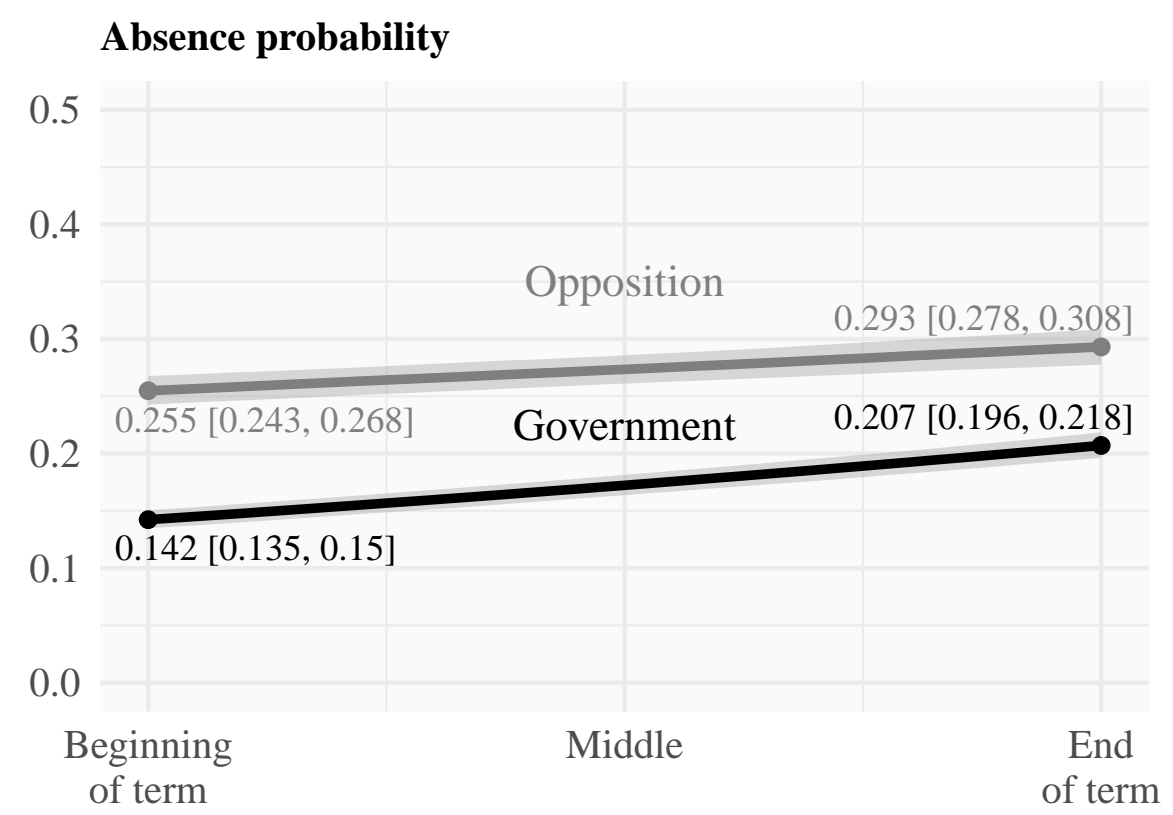

Notes: The figure displays predicted absence probability for government and opposition MPs as we get closer to the next elections (all other predictors held constant at their means or most frequent nominal category). Predicted values (with 95\% confidence intervals) at the beginning and end of term are highlighted. The legislature variable is fixed for 2005-2010, hence the difference from the 0.31 average absence rates across all legislatures. We will return to these differences below. 
Figure 3: Absence probability as a function of electoral cycle for opposition and government MPs

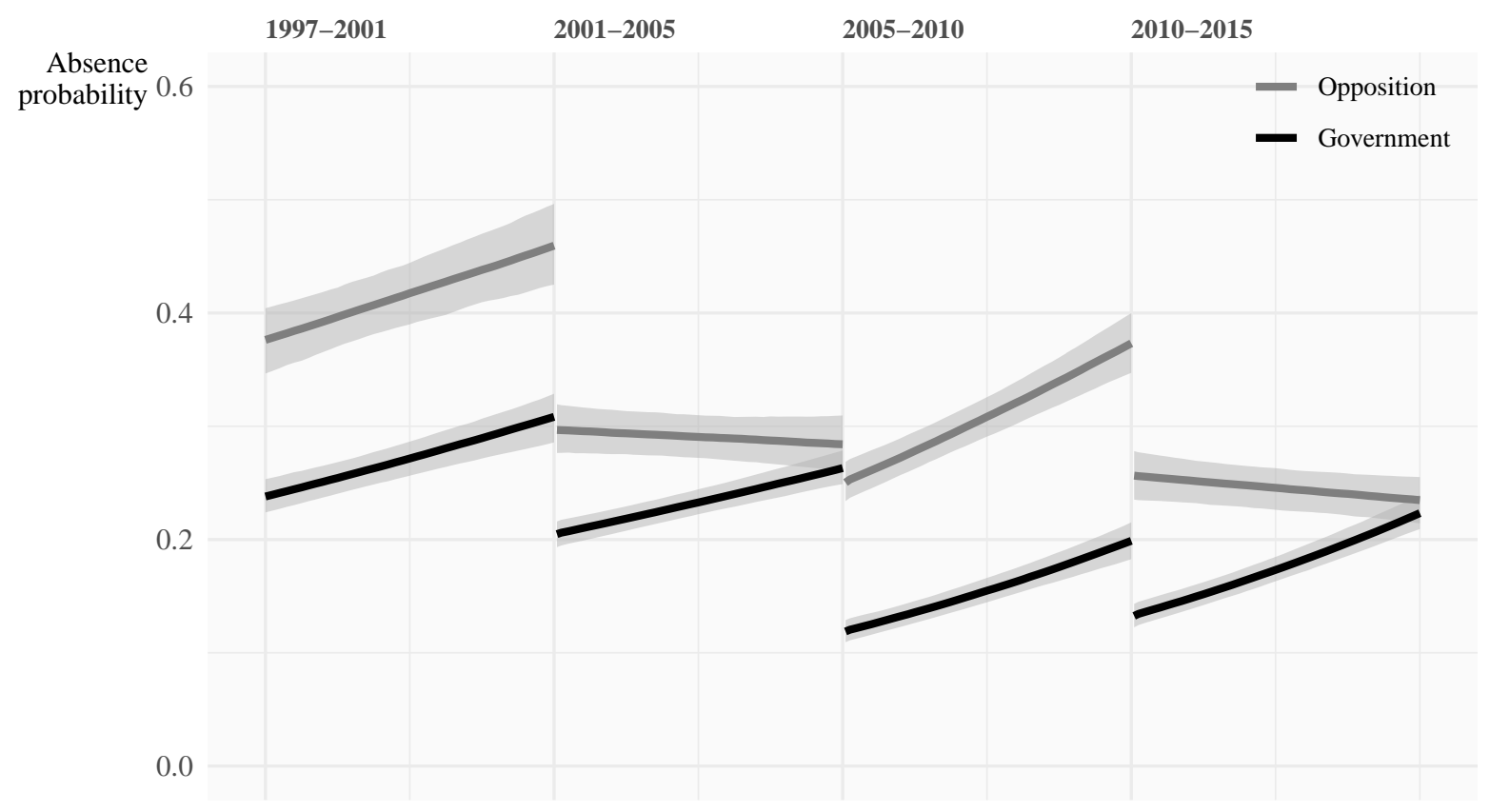

Notes: Full model results reported in Online SI A3 (all other predictors held constant at their means or most frequent nominal category). 
Figure 4: Absence probability as a function of electoral cycle for opposition and government MPs

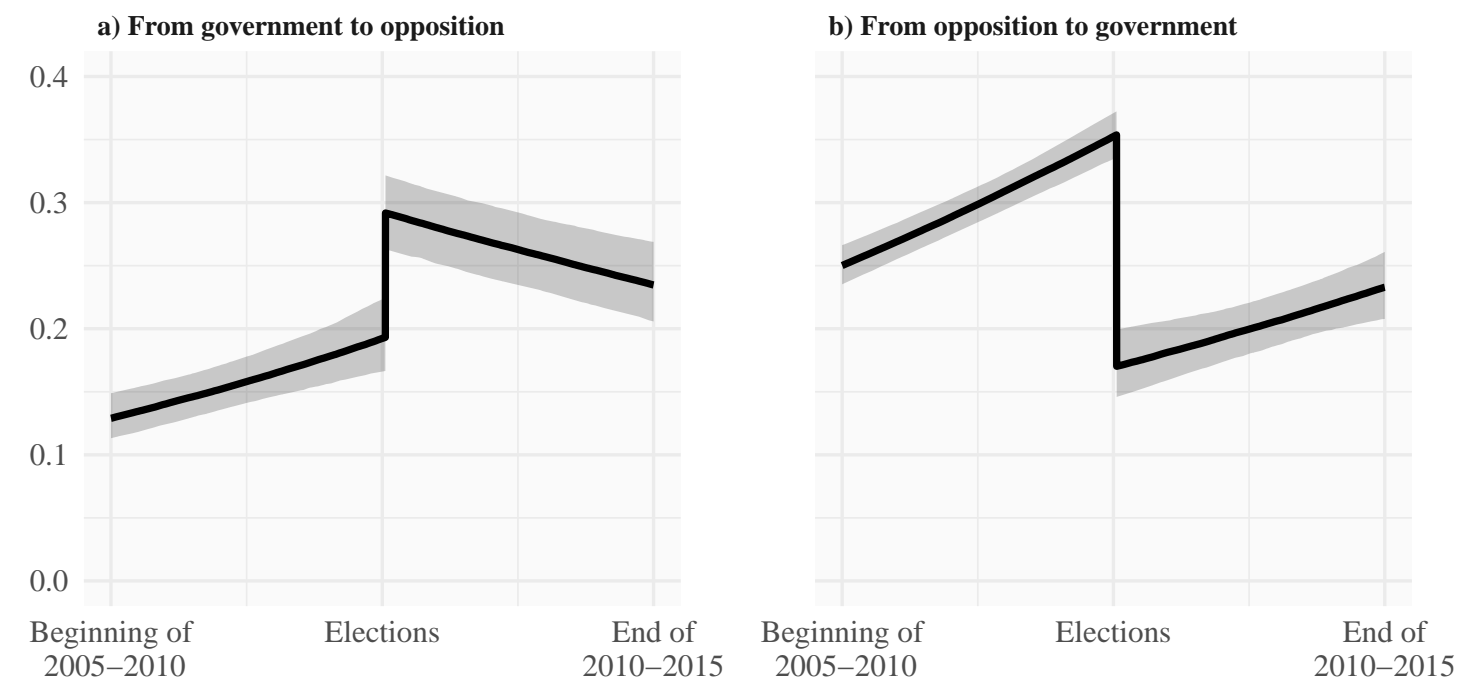

Notes: Full model results reported in Online SI A3 (all other predictors held constant at their means or most frequent nominal category). 
Figure 5: Absence probability as a function of electoral cycle for opposition MPs (party split, within-MP analysis)

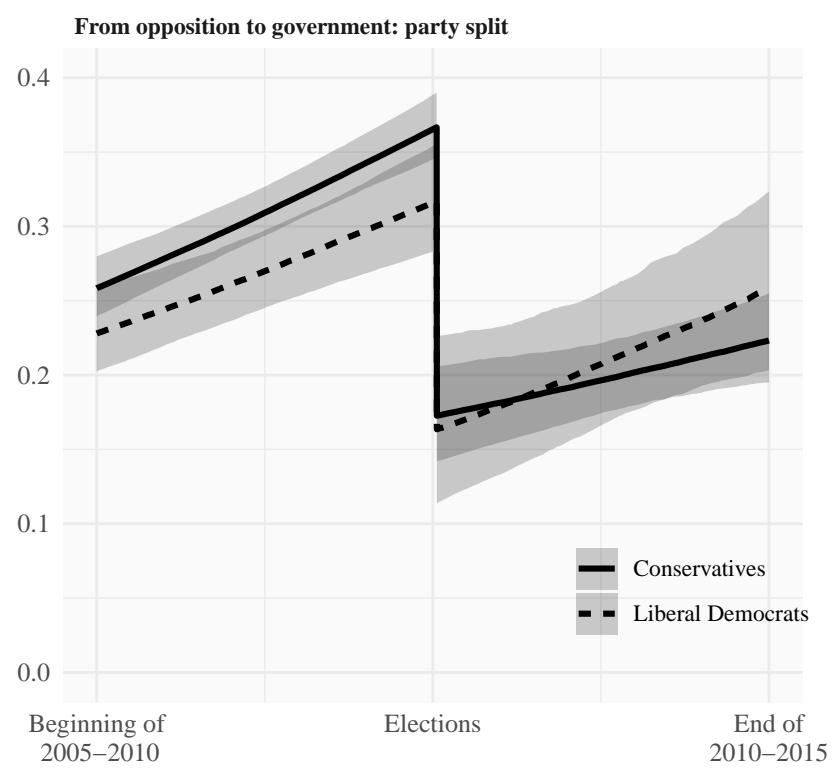

Notes: Full model results reported in Online SI A3 (all other predictors held constant at their means or most frequent nominal category). 


\section{Appendices}

Online Supplementary materials for "Incentives for Non-Participation: Absence in the United Kingdom House of Commons, 1997-2015”. 


\section{A1 Data And Descriptives}

Table A1.1: Number of divisions and MPs

\begin{tabular}{lcccc}
\hline & $1997-2001$ & $2001-2005$ & $2005-2010$ & $2010-2015$ \\
\hline Divisions & 1273 & 1246 & 1288 & 1226 \\
Government MPs & $426 / 381$ & $416 / 381$ & $359 / 300$ & $364 / 313$ \\
Opposition MPs & $243 / 192$ & $243 / 168$ & $291 / 226$ & $298 / 212$ \\
\hline Total MPs & $678 / 573$ & $672 / 549$ & $657 / 526$ & $664 / 526$ \\
\hline
\end{tabular}

Notes: First entry is all data, second entry after all exclusions described in the text. The number of divisions does not decrease when excluding MPs from our analysis.

Table A1.2: Descriptive statistics

\begin{tabular}{lr}
\hline & Statistic \\
\hline Gvt bill division & 0.48 \\
Vote majority & $0.41(0.27)$ \\
Government MP & 0.63 \\
Retiring & 0.16 \\
Seniority & $8.54(8.89)$ \\
Constituency majority & $21(14)$ \\
Constituency distance (in $\mathrm{km})$ & $255(202)$ \\
\hline
\end{tabular}

Notes: Mean and standard deviation of continuous variables; proportions for dichotomous variables (on the scale of long data format). 


\section{A2 Full model Results and detailed Robustness Checks}

Table A2.1: Full model output. (Restricted) Maximum Likelihood estimates of logit coefficients with standard errors in parentheses.

\begin{tabular}{lrc}
\hline & Legislature fixed effects & \multicolumn{1}{c}{ All controls } \\
\hline Intercept & $-0.375(0.032)^{* * *}$ & $-0.871(0.039)^{* * *}$ \\
Next election closeness & $0.299(0.030)^{* * *}$ & $0.191(0.032)^{* * *}$ \\
Government MP & $-0.713(0.031)^{* * *}$ & $-0.725(0.033)^{* * *}$ \\
$2001-2005$ & $-0.240(0.036)^{* * *}$ & $-0.292(0.037)^{* * *}$ \\
$2005-2010$ & $-0.403(0.037)^{* * *}$ & $-0.597(0.037)^{* * *}$ \\
2010-2015 & $-0.508(0.037)^{* * *}$ & $-0.649(0.038)^{* * *}$ \\
Govt. $\times$ closeness & $0.249(0.038)^{* * *}$ & $0.262(0.041)^{* * *}$ \\
Government bill & & $0.140(0.003)^{* * *}$ \\
Thursday & & $0.649(0.005)^{* * *}$ \\
Friday & & $2.983(0.008)^{* * *}$ \\
Monday & & $0.125(0.004)^{* * *}$ \\
Tuesday & & $-0.011(0.004)^{* *}$ \\
Retiring & & $0.298(0.039)^{* * *}$ \\
Constituency majority & & $0.028(0.059)$ \\
Distance & & $0.455(0.070)^{* * *}$ \\
Seniority & & $0.939(0.070)^{* * *}$ \\
\hline AIC & & 2936443.953 \\
BIC & & 2936687.561 \\
Division $\times$ MP & 3131188.166 & 2734621 \\
MPs & 31316.381 & 2173 \\
(Var) MPs & 2734621 & 0.496 \\
(Var) Closeness slope & 2173 & 0.844 \\
(Cov) (Int, Closeness slope) & 0.495 & -0.313 \\
\hline *** $p<0.001{ }^{* *} p<0.01 ;{ }^{*} p<0.05$ & 0.741 &
\end{tabular}




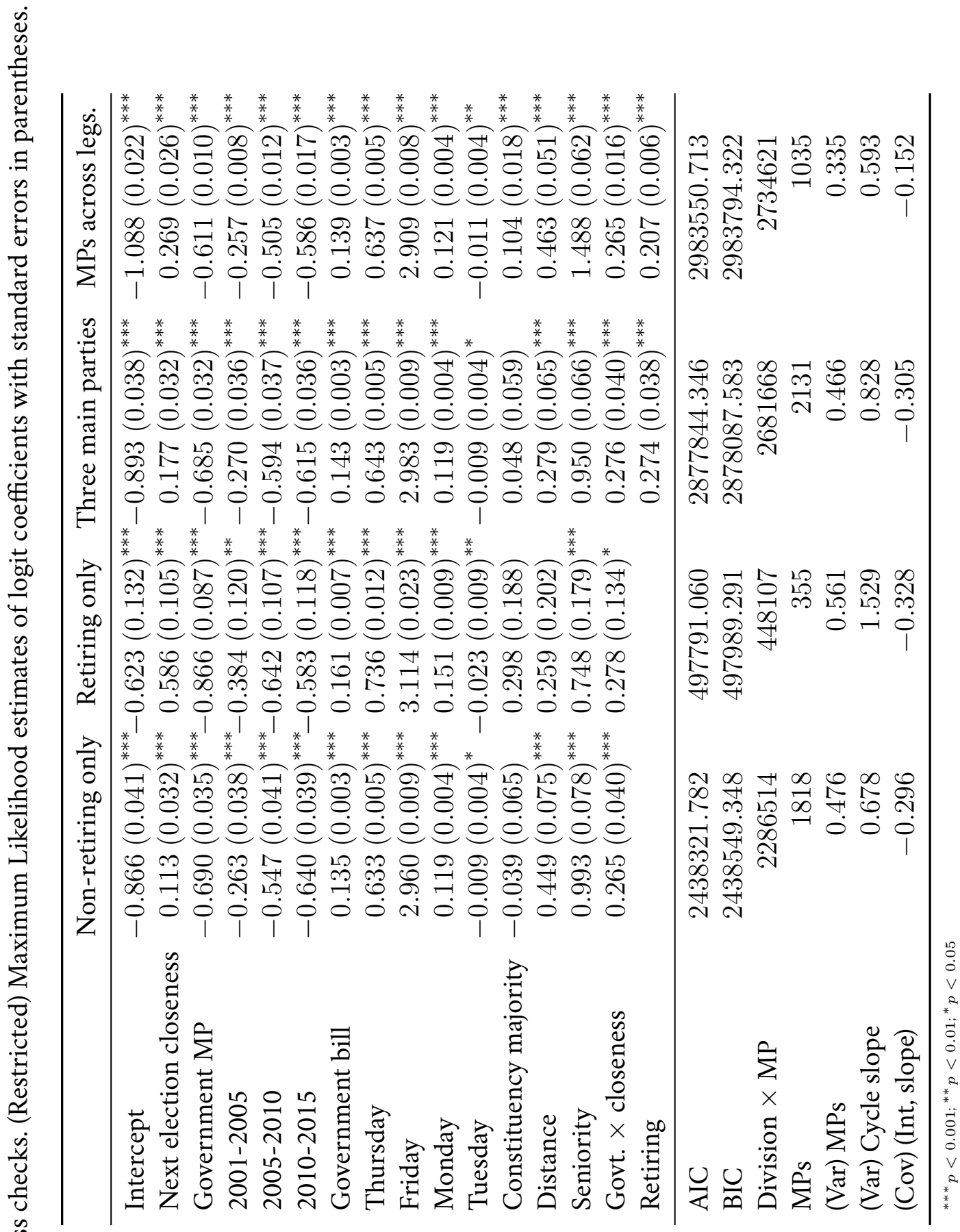




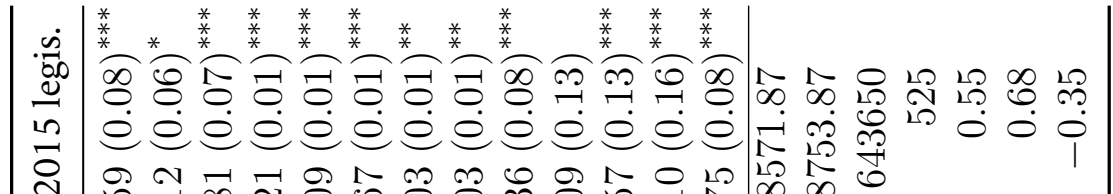

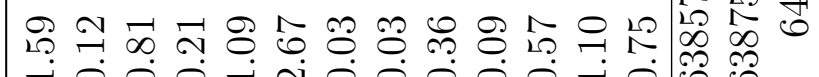
号

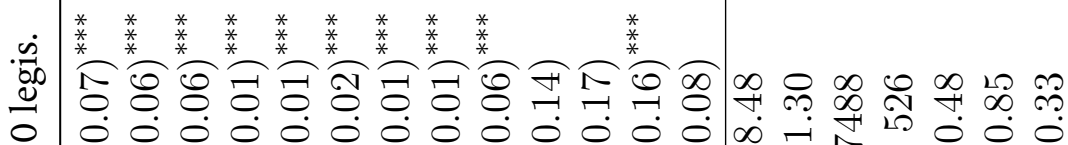

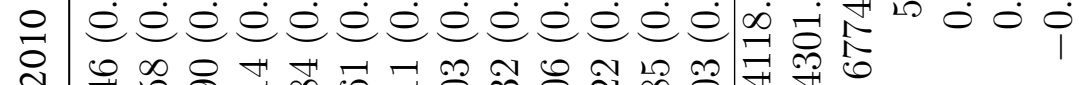

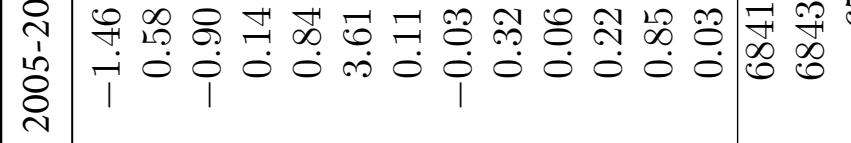

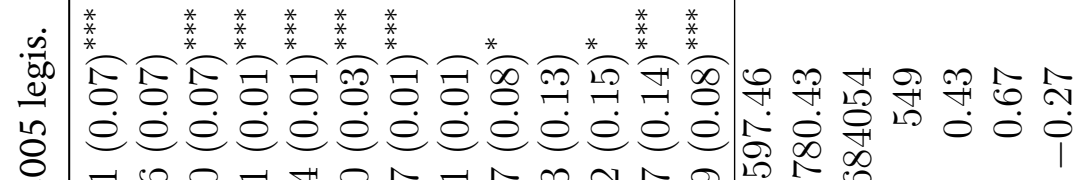
국

官

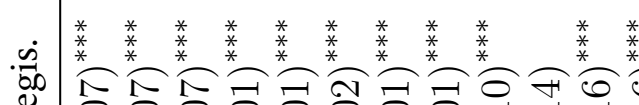

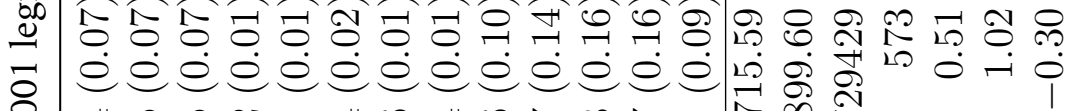

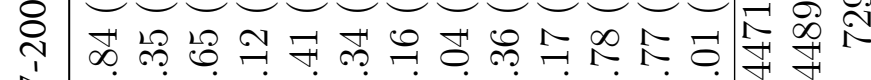

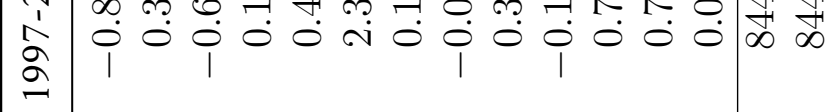




\section{A3 Detalled Within-MP results}

Table A3.1: Hierarchical models of absence probability: within-MP models

\begin{tabular}{lrr}
\hline & $\begin{array}{c}\text { From government } \\
\text { to opposition }\end{array}$ & $\begin{array}{c}\text { From opposition } \\
\text { to government }\end{array}$ \\
\hline Intercept & $-2.275(0.140)^{* * *}$ & $-1.419(0.069)^{* * *}$ \\
Legislature days (all) & $0.947(0.195)^{* * *}$ & $0.980(0.096)^{* * *}$ \\
Legislature days (second) & $-1.542(0.245)^{* * *}$ & $-0.203(0.255)$ \\
Change to second leg. & $0.543(0.089)^{* * *}$ & $-0.973(0.100)^{* * *}$ \\
Government bill & $0.221(0.010)^{* * *}$ & $0.138(0.009)^{* * *}$ \\
Thursday & $1.063(0.018)^{* * *}$ & $0.844(0.017)^{* * *}$ \\
Friday & $3.427(0.024)^{* * *}$ & $2.660(0.021)^{* * *}$ \\
Monday & $0.138(0.014)^{* * *}$ & $0.006(0.012)$ \\
Tuesday & $0.049(0.013)^{* * *}$ & $-0.002(0.011)$ \\
Constituency majority & $-0.201(0.243)$ & $0.012(0.195)$ \\
Distance & $0.195(0.281)$ & $0.365(0.219)$ \\
Seniority & $0.667(0.307)^{* *}$ & $0.626(0.211)^{* *}$ \\
\hline AIC & 251788.839 & 304983.908 \\
BIC & 252019.055 & 305216.162 \\
Division $\times$ MP & 258942 & 284082 \\
MPs & 103 & 113 \\
(Var) MPs & 0.568 & 0.166 \\
(Var) (all) Leg. days & 4.112 & 0.859 \\
(Var) (second) Leg. days & 6.520 & 7.223 \\
(Var) Change to second leg. & 0.627 & 1.027 \\
(Cov) Int., Leg. days & -0.747 & -0.232 \\
(Cov) Int., (second) Leg. days & 0.735 & 0.237 \\
(Cov) Int., Change to second & -0.044 & -0.077 \\
(Cov) Leg. days, (second) Leg. days & -4.394 & -1.742 \\
(Cov) Leg. days, Change to second & 0.906 & \\
(Cov) (second) Leg. days, Change to second & & 0.277 \\
\hline & & \\
\hline
\end{tabular}

(Restricted) Maximum Likelihood estimates of logit coefficients with standard errors in parentheses. ${ }^{a}$ Second legislature refers to $2010-2015 .{ }^{* * *} p<0.001 ;{ }^{* *} p<0.01{ }^{*} p<0.05$ 